\title{
Film
}

\section{Electricity crackles with authenticity}

Since the dawn of cinema, epilepsy has been employed by film makers as shorthand to convey madness, stupidity, or both. In 1929, in one of the first British talking pictures (To What Red Hell?), an aristocratic young man named Harold murders a woman while having a seizure. In the climax of the film, Harold istold he has epilepsy and that the murder is not his fault; his immediate relief that he is not morally culpable for his crime is short-lived. Within seconds, he realises that the diagnosis means he will be a danger to his friends, family, and indeed anyone he may come into contact with. In the next scene he does what he sees as the decent thing and shoots himself. It's a shocking scene, even when viewed today; we can only imagine what audience members with epilepsy felt when they watched this film back in 1929 with their friends and family. Elements of this grim portrayal have been repeated in numerous cinematic treatments of epilepsy throughout the 20th century.

Cinematic portrayals of epilepsy haven't just been criticised for reinforcing erroneous stereotypes of the disease and the people who suffer from it. These films also face the perennial problem of how to represent the seizures themselves. The human body is incapable of accurately reproducing, on demand, the neuronal synchrony that drives a tonic-clonic seizure. For anyone familiar with the real thing, the sight of actors writhing on the floor, thrashing around and foaming at the mouth with camellike viscosity and volume, can be distracting to say the least.

Electricity, a new British film partly funded by the Wellcome Trust, is the latest film to feature the dramatic potential of epilepsy. Based on the acclaimed novel by Ray Robinson, the film makers have avoided many of the pitfalls that have ensnared other epilepsy films. The casting of supermodel-turned-actress Agyness Deyn to play Lily, the central role, ran the risk of creating the archetypal beautiful yet vulnerable heroine. However, there is no trace of a supermodel in Lily; Deyn's transformation from fashion goddess to ordinary northern lass is helped in no small part by the maverick wardrobe department, which managed to source surely the most unflattering jacket ever to have graced the silver screen. It is unclear whether Lily's outerwear is a subtle reference to the psychedelic graphics of the epilepsy tests that proliferate on YouTube or her colourful character, but it certainly makes you forget that you are watching a supermodel.

Deyn is entirely convincing as an ordinary young woman on a quest to find her brother. Her epilepsy gets in the way, but the character is neither defined nor ennobled by it. There's no squeamishness here. The film confronts, square on, the incontinence, memory problems, inherent vulnerability, and horrific injuries that can be associated with uncontrolled seizures, but the story moves along regardless, just as life does after a real seizure.

The seizures are cleverly filmed, with the camera closely focusing in on only parts of Lily's body, such as her face or hands, when she has a seizure. As we don't see the whole effect, we can fill in the gaps with authenticity. Distortions in sound and light, and scenes of bold, blank, nothingness also convey the experience of the seizures from Lily's perspective. The result is both disconcerting and impressive.

Electricity is not perfect, of course. The early scenes in an amusement arcade and later in a nightclub, will reinforce the connection between flashing lights and epilepsy in the audience's subconscious, even if the trigger is not explicit in the film. Less than $5 \%$ of people with epilepsy have photosensitive epilepsy, and Lily does not seem to be one of them (her doctors tell her she has temporal lobe epilepsy). There can be no other neurological condition where such a rare manifestation is so well known by the general public, whereas the far more common variant of focal seizures often goes unrecognised.

But it is not for the medical profession to dictate cinematic content. Who would want to watch a film so accurate in every detail that it mimicked a clinic consultation? However, it is satisfying when medical portrayals are sufficiently accurate not to distract from the narrative of a film for those in the know. Electricity more than delivers on this score. In fact I would go further and defy anyone to come away from watching the film without anewappreciation for whatitisliketolivewith seizures.

Sallie Baxendale

For more on the portrayal of epilepsy in the movies see Lancet Neuro/2003; 2: 764-70.

For more on psychedelic graphicstests seeEpilepsy Professiona/2008; 9: 22-24. 